\title{
Mind over Body: Positive attitude and flexible control beliefs on positive aging
}

\author{
Weining C. Chang ${ }^{1}$, Yvonne Toh ${ }^{2}$, Qian Qian Fan ${ }^{3}$, Annabel S. H. Chen ${ }^{4}$ \\ ${ }^{1}$ Duke-National University of Singapore Graduate School of Medicine \& Institute of Mental Health, \\ ${ }^{2}$ National University of Singapore, ${ }^{3}$ Nanyang Technological University, ${ }^{4}$ Nanyang Technological \\ University
}

Corresponding author: Weining C. Chang, PhD. Duke-National University of Singapore Graduate School of Medicine and Institute of Mental Health, Republic of Singapore. Email address: weiningchu.chang@duke-nus.edu.sg

\begin{abstract}
Positive attitude toward aging and a flexible coping style have been found to facilitate successful aging. Cognitive beliefs such as hope and positive attitude towards aging has been found to slow down the negative impact of aging on brain functions; furthermore, the negative effect of stress on aging can be ameliorated by the moderating effects of goal oriented and situation driven selection and compensation of different coping strategies. An empirical study conducted in Singapore is presented. Using both the primary control belief strategies and the secondary control beliefs and strategies, Singaporean elderly studied (ages of 55 and 84 (males: $N=81$; females: $N=50$ ) showed positive adjustment. Different coping strategies showed different effects on different symptoms assessed by the General Health Questionnaire. We trace the philosophical origins of the Asian conceptualization of life-span development and the positive beliefs and values on aging to show that: In this modern Asian community, the traditional beliefs and values still persist. With a more positive conceptualization of aging, the Singaporean elderly are actively engaging in situation-oriented and goal-driven selection of a variety of coping strategies to manage their aging.
\end{abstract}

\section{Introduction}

Recently, much attention has been focused on the cognitive mediators between stressor and stress responses (Lazarus \& Folkman, 1984). Scientific enquiry into the process of successful aging has found the relevance of psychological control beliefs for health and aging (Lachman, Neupert, \& Agrigoroaei, 2011). Literature in this area suggests the adaptive functions of internal locus of control (Rutter, 1966) and primary control strategy - that is, to change the situation in order to suit the goal of the self (Rothbound, Weisz, \& Snyder, 1982) often predicts positive outcomes. The current paper explores an alternative approach to the sense of control by investigating flexible selection of specific control beliefs and the related control strategies (Lefcourt, Von Baeyer, Ware, \& Cox, 1979) as a way to optimize the benefit during critical challenges in life development (Baltes, 1997; Baltes \& Staudinger, 2000) and successful aging (Baltes \& Carstensen, 1996). We especially focus on a less known form of control: secondary control - to change some aspects of the self in order to adjust to the situation (Rothbound et al., 1982). Furthermore, we propose a flexible, situation-driven, alternating use of both primary and secondary control as the effective coping reactions to the challenges of aging. We propose that the healthy elderly use a combination of different coping strategies in order to minimize the difficulty brought about by ageing to maximize their functioning (Staudinger, Marsiske, \& Baltes, 1995). We further propose that a series of cognitive factors - a positive attitude toward aging (Levy \& Langer, 1994), and flexible use of situation-fit coping strategies serve as cognitive mediators that facilitate positive ageing.

\section{Primary -Secondary Control Framework}

\section{Multifaceted sense of control}

In this context, primary control is defined as a belief that the individual can enhance his/her welfare by influencing existing external realities, such as symptoms of aging. Secondary control is defined as the belief that the individual can enhance his/her welfare by accommodating to existing situation via changing one's own cognition, affects and/or behaviors (Weiz, Rothboum, \& Blackburn, 1984).

The belief that people are in control of desired outcomes is a hallmark of American culture (Bandura, 1977) and the concept of agency - direct and active control over life events, is pervasive in North American literature (Lachman et al., 2011). Testing the concept of agency, Hitlin, Drickson, and Brown (2015) identified two positive outcome producing cognitive processes that build upon current focus on personal control within the 
stress-and-coping process model: (1) "Subjective vitality" and (2) a forward-looking orientation ("optimism"). These authors found an interesting paradox, where adolescents with higher health based agency earlier on have significantly higher status attainment outcomes, but early these mental health advantages disappear over the transition to adulthood. These observations suggest that older adults may benefit from other forms of control.

It has been found that older adults are less likely than the young to believe that there are things that can be done to directly control aging-related declines in areas such as memory (Schultz, R., \& Heckhausen, 1996). Within aged groups, individual differences in control beliefs and health outcomes suggest potential mechanisms linking perceived control and positive outcomes. The mediating mechanisms for positive outcomes include healthy behaviors, dieting and physical activity that are specific to the realistic perception of the aging process (Wilcox et al., 2009).

Rothbaum et al., (1982), on the other hand, proposed a somewhat broader view of the control beliefs. Individuals sometimes attempt to align themselves with existing situation leaving the external reality unchanged but exerting control over the psychological impact on the individual. They used the term "secondary control" to refer to a broad range of these alternative paths.

Direct and indirect sense of control

Japanese psychologists Azuma (1984) and Kojima (1984), however, suggested that primary and secondary control styles do not exhaust the possibilities of styles of psychological control. These Asian scholars felt that the dichotomy of primary and secondary control reflects an American orientation that focuses more on the direct assertion of the individual to change the situation. More importantly, they noted that the Japanese, often attempt a form of indirect "primary control", that is, changing the world through indirect means. Along the same line of argument, we further propose that a finer differentiation has to be made between those who relinquish direct active control over events and experience a sense of helplessness and those who gave up attempts to change the external reality but maintain an active "control" over the self and are able to select either self-directed or event-directed strategies of control in order to optimize the welfare of the individual. The latter is not "helpless" but represents an alternative path to self-enhancement and goal accomplishment. Baltes and Freud (2003) consider this flexible and goal driven practice to be a form of "wisdom" - for successful life-span development (Baltes, \& Freud, 2003).

Multifaceted (specific) goal-oriented and situation bound locus of control.

Based on the above arguments, we propose a style of situation oriented flexibility in the control strategies; we suggest that control strategies should be defined with a goal-oriented and situation-bound approach. In that, the sense of control can be looked at both as a "generalized belief" about things in the world (Rutter, 1966) and a specific goal and situation bound consideration (Lefcourt. et al., 1979). We hypothesized that the Chinese elderly exercise a flexible use of both primary and secondary sense of control, driven by their beliefs about the aging process and outcomes. In addition, we further hypothesized that a positive attitude toward aging and a flexible use of different control strategies facilitate successful aging. Our proposal is similar to the Wisdom model of aging. In life span development, Baltes and colleagues (for instance, Baltes \& Baltes, 1990; Baltes \& Staudinger, 2000; Freud \& Baltes, 2002) have noted that healthy human beings use the strategy of selection-and-compensation in order to achieve optimal functions given the resources and challenges in life. Similarly, we propose that the healthy elderly use a variety of strategies to cope with different challenges in aging. These strategies may produce different results in different aspects of life, but the combined effect is to optimize adaptive functioning and to compensate for the challenges faced that are deemed beyond one's control.

Attitude toward ageing

The world populations are facing a "silver Tsunami" with rapidly aging society. More attention has been paid to the aging process and its management. Recent advances in medicine and biomedical technology has radically changed our ways of managing the aging process (Cartensen \& Charles, 2003; Levy, 2003; Luszcz, Anstey, \& Ghisletta, 2015; Seeman, Unger, McAvey, \& de Leon, 1999). These advances brought in changes in our conceptualization and attitudes toward aging.

In the past, people's life course were scripted with rigid regulations leaving little room for individual choices for different life styles -and coping strategies to manage their lives (Baltes \& Freud, 2003, pp. 33). The contemporary conceptualization affords much more freedom and flexibility for the individual's choices of life styles, control beliefs and coping strategies. The choices are based on the individual constructing the meanings and management of life's challenges.

Consistent with the flexibility of individual choices of life management, Baltes and colleagues proposed that there is no "static end state of life"(Baltes, \& Freud, 2003, pp. 35), that the life itself can be conceived to be never ending but ever progressing towards more maturity than declining. Aging is not to be feared but to be 
experienced as another developmental stage in life that can be managed wisely and effectively for wisdom and wellbeing (Carstensen \& Charles, 2003).

This new conception of the end-state of human development has been proposed as an underlying guiding mechanism for successful aging. Life is a dynamic process of continuous pursuit of wisdom and happiness through learning. The developmental course includes both selection of goals and the pursuit of goals through active construction of strategies. Furthermore, development is no longer conceived as an individual endeavor but also include the development of others (Baltes \& Freud, 2003). This dynamic model of human development and the promotion for life-long learning to achieve the wisdom and wellbeing through selection of goals attainment strategies has been the teaching of Confucianism throughout the centuries (Tu, 1985). Asian philosophy of Taoism (Lau, 1963) and Buddhism further believes that aging is but a season in the individual's life as seasons in the year. Birth, aging illness and death are all part of Samsara - cycle of life (Lin, 2009). The belief in the cyclic nature of life and death, birth and aging as part of the natural phenomenon helps the believers of these philosophies to adopt an attitude toward aging that is less prejudiced- less characterized by negative beliefs about the physical and psychological changes brought about by aging.

Empirical studies have also identified a number of "benefits" that come with aging (Carstensen \& Charles, 2003). For instance, Mather and Carstensen (2005) in a review article found that as people get older, they experience fewer negative emotions. The same positive emotion effect has been found in Chinese older adults from an eye-tracking study (Wang, He, \& Jia et al, 2015). Older adults show more emotionally gratifying memory distortion for post choices and autobiographical information than younger adults do. The elderly's memories seem to be due to their greater focus on emotional regulation and to be implemented by cognitive control abilities and motivation.

Likewise, Seeman, Unger, McAvay and Medes, de Leon (1999) found that men and women between 70-79 reported that their self-efficacy beliefs have significantly changed their perception of functional disability or ability, independent of underlying abilities. Furthermore, Wilcox et al., (2009) found that positive attitude toward aging led to the identification of physical activities and dietary practices that can promote brain health.

Summarizing the above literature on positive attitudes and related control beliefs, we conclude that these cognitive factors are crucial in the elderly's adjustment to aging or even benefit from the aging process by positive outlooks and working effectively with the aging process. More importantly, the successfully aging elderly, no longer naively believe exclusively in the direct active control but wisely engaged in multi-faceted, specific goal oriented control beliefs and coping strategies. They are achieving the life "wisdom" taught by Confucius (circa, 250BC) (Lin, 2009; Tu, 1985) and contemporary scholars (Bales \& Freud, 2003).

To evaluate the above proposed relationship between positive outlook and related control beliefs in Asian elderly populations, we conducted an empirical study in a community sample of Singaporean elderly. In this study, we examined how the primary and secondary control belief strategies are related to general health dimensions.

\section{Participants}

\section{The Empirical Study}

One hundred and thirty-one elderly Chinese Singaporeans between the ages of 55 and 84 (males: $N=81$; females: $N=50$ ) responded to the questionnaire. The participants were approached in places usually frequented by the elderly, for example, at the void-deck of their apartment buildings or in the parks where they usually visit. Residents of nursing homes were not included for better control over the functional status over ageing. The participants' native language was also controlled by limiting the interview to either English or some form of Chinese language. Some of the participants were illiterate - which is not uncommon for Singaporeans who grew up before 1965 - the founding of the new republic that introduced national compulsory education in this formal British Colony.

Instruments

Primary-Secondary Control Belief Scale (Chang, Chua, \& Toh, 1997): Chang, Chua, and Toh (1997) constructed the Primary-secondary control scale in Singapore based on the conceptualization and manifestations of control beliefs of situational challenges in the daily life. The Primary control belief subscale consists of 17 items; the secondary control scale consists of 19 items (see Table 1). The internal reliability of the Primary Control subscale was found to be Cronbach Alpha $=.84$ and the internal reliability of the Secondary Control Subscale was Cronbach Alpha $=.73$.

Attitude towards Aging: The measurement of the attitude towards ageing used in the current study was modeled after the method used by Levy and Langer (1994). The following attitude dimensions were used: 
internality, positivity and capacity. The participants were asked to generate the description of ageing. Responses were judged by two blind raters and scored along the dimensions mentioned earlier. The inter-rater reliability was found to be 0.73 .

Concurrent Control Measure: Internal locus-external locus of control by Rotter (1966). The internal-External Locus (I-E) Scale used in the present stud consists of twenty-three forced-choice items. Each item consists of a pair of statements: one representing external locus of control the other one representing internal locus of control. In other words the response format is such that internality and externality are operationalized into two poles of a one-dimensional variable.

Adaptive outcome measure: General Health Questionnaire (GHQ): The GHQ was used to measure general adjustment. It is a twenty-eight-item scale measuring four dimensions of general health: somatic symptoms, anxiety, and insomnia, social dysfunction and severe depression (Goldberg \& Hillier, 1979). Each subscale consists of seven items. A Cronbach alpha of 0.95 was found for the present sample of respondents. Subscale alphas were 0.89 , for somatic symptoms, 0.90 for anxiety and insomnia, 0.85 for social dysfunction and 0.91 for severe depression.

Procedure

Potential participants were approached in their usually frequented places. The multi-lingual experimenter (YL. Toh) explained the purpose of the study and then solicited the participation. For participants who were illiterate, the experimenter read the questionnaire to them verbally in the language of the participants' choice.

Adaptive outcomes

\section{Results}

Table 2 presents a correlational matrix of the variables studied. Stepwise regression analyses were carried out on the data with the four-dimensions of the GHQ as the outcome measure. We did not have a priori hypotheses about relationship between the different controls and different dimensions of GHQ: Stepwise regression assesses the relative correlation between predictors of the dependent variable to determine the order in which the predictors are entered into the model (See Table 3).

It was found that different control beliefs showed differential effects on different domains of adjustment. Secondary control was found to be the most important predictor in reducing somatic symptoms and anxiety and insomnia.

Primary control beliefs were found to contribute significantly to ameliorating social dysfunction and severe depression.

Antecedent condition: Positive attitude toward aging was found to significantly predict secondary control $(\mathrm{r}=0.17 ; 2.8 \%$ of variance). Positive attitude however is not significantly related to primary control; nor is it related to internal-external locus of control.

Concurrent Control Beliefs: Secondary control is not significantly related to the internal-external control measure. Secondary control is significantly related to primary control ( $r=0.60,36 \%$ of variance). Means and standard deviations of different control beliefs indicate that the subjects are more internal in their locus of control (see Table 4).

\section{Conclusion and discussion}

The Chinese elderly surveyed in the present study used a combination of different control belief systems. They used these different control beliefs under different situations and for effects on different specific outcomes. Each type of control beliefs correspondingly showed adaptive effects on different aspects of the outcome measure: for instance, secondary control belief helped to reduce insomnia and psychosomatic symptoms - emotional and stress symptoms. Our finding suggests that the adaptive effect of secondary control is mainly in serving as a cognitive moderator between stressful events and stress-responses. Secondary control belief was not shown to be a significantly effective moderator between stressful events and major depression, nor was it effective in problem solving and social adaptation. We however propose that secondary control beliefs may be helpful in problem solving in an indirect way, possibly by reducing the negative emotions that detract the individual from effective task engagement.

The use of secondary control is significantly correlated with positive attitude toward aging: this finding helps us to delineate the antecedents of secondary control. As mentioned in the introduction, we proposed that there are multiple sources contributing to the selection of different kinds of control beliefs and coping strategies. As suggested (Weisz et al., 1984), there is a recipe of different control beliefs available to a given individual. It is the controllability of the situation and the dynamic use of matching the control strategy with the situation - i.e., 
selection and compensation (Freud \& Baltes, 2002) that optimize the health conditions of the elderly.

This was further supported by the fact that secondary control was found to be positively correlated with primary control which, in turn, positively correlated with internal locus of control. This suggests that the use of secondary control was an active decision reflecting the internal locus of control rather than a passive giving up. This suggests that the secondary control in the Chinese elderly is conceptually akin to the active sense of control but only differ in strategies of coping. They exercised optimal use of both primary and secondary control beliefs for different aspects aging; this in turn produces effects on different aspects of health. This flexibility of using different coping strategies to manage different aging health symptoms further prompts us to think about aging and its management not as a one dimensional process but as multi-faceted and multi-strategy life management.

The present study demonstrated that a set of social cognitive factors - attitudes and coping beliefs, predict significant positive effects on somatic functions, stress and social functions of the elderly surveyed. These cognitive factors in combination produced $13.7 \%$ of variance in the overall results of GHQ - an effect far from being trivial. This suggests that encouraging positive thinking and flexible ways of coping could be an effective strategy to aid the elderly in successful ageing.

Further work is needed to examine the antecedents of perceived control in later life and the implications of control beliefs in other aging-related domains (Fernandez-Ballesteros, 2003; Lachman, Neupert, S. D., \& Agrigoroaei, 2011; Levy, 2003). We further propose that future effort should be directed towards assessing the effects of these cognitive factors on the brain (Park \& Gutehess, 2006) to gain a deeper understanding of the mechanisms of aging and successful aging. The relationship between cultural beliefs, traditional philosophies, control beliefs and the functions of the brain and its neural substrates needs to be investigated and documented to provide a more comprehensive understanding. Furthermore, the behavioral strategies and practical life management measures inspired by positive aging attitude and the practical, flexible control beliefs and coping strategies should also be systematically documented to provide lessons for successful aging.

References:

Azuma, H. (1984). Secondary control as a heterogeneous category. American Psychologist, 39(9), 970-971.

Baltes, P. B. (1997). On the incomplete architecture of human ontogeny: Selection, optimization, and compensation as foundation of developmental theory. American Psychologist, 52, 366-380.

Baltes, P. B., \& Baltes, M. M. (1990). Psychological perspectives on successful aging: The model of selective optimization with compensation. Successful aging: Perspectives from the behavioral sciences, 1, 1-34.

Baltes, M. M., \& Carstensen, L. L. (1996). The process of successful aging. Aging and Society, 16, 397-422.

Baltes, P. B., \& Freud, A. M. (2003). Human strength as the orchestration of wisdom and selective optimization with compensation. In L. G. Aspinwall., L. G., and U. M. Staudinger (Eds.). A psychology of human strengths: Foundamental questions and future directions for a positive psychology.(pp. 23-36), Washsington, D. C. : American

Baltes, P. B., \& Staudinger, U. M. (2000). Wisdom: A mtaheuristic (pragmatic) to mind and virtue toward excellence. American Psychologist, 55, 122-136.

Bandura, A. (1977). Self-efficacy: Toward a unifying theory of behavioral change. Psychological Review, 84, 191-215.

Carstensen, L. L., \& Charles, S. T. (2003). Human aging: Why is even good news taken as bad?. In Aspinwall., L. G., and U. M. Staudinger (Eds.). A psychology of human strengths: Foundamental questions and future directions for a positive psychology.(pp. 75-86), Washsington, D. C. : American Psychological Association.

Chang, W. C., Chua, W. \& Toh, Y. (1997). The concept of psychological control Progress in Asian Social Psychology, 1, 95-117.

Freud, A., \& Baltes, P. B. (2002). Life management strategies of selection, optimization, and compensation. Measurement by self-report and construct validity. Jounral of Personality and Social Psychology, 82, $642-662$.

Goldberg, D. P. \& Hillier, V. F. (1979). A scaled version of the General Health Questionnaire. Psychological Medicine, 9(1), 139-145.

Hitlin, S., Drickson, L. D., \& Brown, J. S. (in press) Agency and mental health: A Transition to adulthood paradox. Society and Mental Health.

Kojima, H. (1984). A significant stride toward the comparative study of control. American Psychologist, 39(9), 972-973.

Lachman, M. E., Neupert, S. D., \& Agrigoroaei, S. (2011). The relevance of control beliefs for health and aging, 
Handbook of the psychology aging, 7, 175-190.

Lau, D. C. (1963). DaoTe Ching (Laotzu, circa 500 BC) translated by D. C. Lau, . England, UK: Penguin Books.

Lazarus, R. S., \& Folkman, S. (1984). Stress, appraisal and coping. New York: Springer.

Lefcourt, H. M., Von Baeyer, C. L., Ware, E. E., \& Cox, D. J. (1979). The multi-dimensional-multi-attributional causality scale: The development of a goal specific locus of control scale. Canadian Journal of Behavioral Science, 11, 286-304.

Levy, R. (2003). Mind matters: Cognitive and physical effects of aging self-stereotypes. The Journals of Gerontology Series B: Psychological Sciences and Social Sciences: 58(4), 203-211.

Levy, B. \& Langer, E. (1994). Aging free from negative stereotypes: Successful memory in China and among the American deaf. Journal of Personality and Social Psychology, 66(6), 989-97.

Lin, Y. T. (2009). The wisdom of China. (edited and annotated by Y. T. Lin, Beijing, China: Foreign Language Education and Research Publisher.

Luszcz, M. A., Anstey, K. J., \& Ghisletta, P. (2015). Subjective beliefs, memory and functional health: Change and associations over 12 years in the Australian longitudinal study of aging. Gerotology, 61(3), 241-250.

Mather, M., \& Carstensen, L. L. (2005). Aging and motivated cognition: The positivity effect in attention and memory. Trends in cognitive Sciences, 19(10), 1364-1366.

Park, D., \& Gutchess, A. (2006). The cognitive neuroscience of aging and culture. Current Directions in Psychological Sciences, 15(3), 105-108.

Rothbaum, F. M., Weisz, J. R. \& Snyder, S. S. (1982). Changing the world and changing the self: A two-process model of perceived control. Journal of Personality and Social Psychology, 42, 5-37.

Rotter, J. B. (1966). Generalized expectancies for internal versus external control of reinforcement. Psychological Monograph: General and applied, 80(1), 1.

Seeman, T. E., Unger, J. B., McAvay, G., \& de Leon, C. F. M. (1999). Self-efficacy beliefs and perceived decline in functional ability: McArthur studies of successful aging. The Journal of Gerontology Series B: Psychological Sciences and Social Sciences, 54(4), 214-222.

Schulz, R., \& Heckhausen, J. (1996). A life span model of successful aging, American Psychologist, 51(7), 702-714.

Seligman, M. E. P. (1975). Helplessness. San Francisco: Freeman.

Staudinger, U. M., Marsiske, M., \& Baltes, P. B. (1995). Resilience and reserve capacity in later adulthood: Potentials and limits of development across the life span. In D. Cicchetti, \& D. Cohen (Eds.) Developmental psychopathology: Vol. 2, Risk, Disorder and adaptation (pp. 801-847). New York: Wiley.

Tu, W., (1985). Confucian thought: Selfhood as creative transformation. Albany State University of New York Press. Weisz, J. R. Rothbaum, F. M., \& Blackburn, T. C. (1984). Standing out and standing in: The psychology of control in America and Japan. American Psychologist, 39(9), 955-970.

Wilcox, S., Sharkey, J. R., Matthews, A. E., Ladkitka, J. N., Ladkitka, S., Longsdon, R. G., ... Liu, R. (2009). Perception and beliefs about the role of physical activity and nutrition on brain health in older adults. The gerontologist 49(S1), S61-S71.

Wang, J., He, L., Jia, L., Tian, J., \& Benson, V. (2015). The positive effect is present in older Chinese adults: Evidence from an eye racking study. PLoS ONCE, 10(4): e0121372. Doi:10.1371/journal pone.0121372. 
Items

1.I look for something good in that which has has happened.

2.I regard the event as an opportunity for me to learn more about life.

3. I try to come up with a plan of action to alter the situation.

4.I interpret the event as a chance to build up my determination.

5. I talk to someone who can tell me something concrete about how to deal with it.

6.I interpret the event as an opening for increasing my ability to overcome greater problems in the future.

7. I try to see it in a different light, to make it seem more positive.

8. I pray to some spiritual/powerful being whom I believe can change the situation.

9. I think hard about how to change the situation to suit myself.

10. I accept that it has happened.

11. I talk to somebody who has the power to change the situation.

12. I accept that it cannot be changed.

13. I tell myself that though I cannot control the situation, I can still control the impact it has on me.

14. I find that what has happened have already happened. No point brooding over it.

15 I find out the cause in order to deal directly with the problem.

16. I find it best to accept the reality of the fact that it has happened.

17. I seek help from somebody who has the authority to bring about a change to the situation.

18. I find it pointless to try to change the situation.

19. I try to alter my expectations so as to avoid future disappointment.

20. I pray to some spiritual powerful being for power and wisdom to do something to the situation.

21. I pray to some spiritual. Powerful being to feel comforted.

22. I concentrate my efforts on doing something about it.

23. I take additional action to try to get rid of the problem.

24. I talk to my friends to feel comfortable.

25. I interpret the event as a learning experience because not everyone gets to experience it.

26. I make an effort to find ways of changing the situation.

27. I find that worrying about the event can bring me nowhere... what has happened has happened.

28. I try to influence somebody who has the power to change the situation to help me.

29. I try to find comfort in my religion.

30. I put aside other activities so as to concentrate on changing this situation.

31. I interpret the event as an opportunity for me to grow as a person.

32. I try to change myself to fit in the situation.

33. I find out more about the situation in order to increase the possibility of changing it.

34. I work hard at it in order to change the situation

35. I interpret the event as part of the process of learning more about myself.

36. I find out more about the situation so as to enhance my ability to alter it.

37. I read up on how I can do something concrete about the situation.

Table 2. Correlation matrix of variables studied: Adapting to aging

\begin{tabular}{lllllll}
\hline Variables & $\begin{array}{l}\text { Primary } \\
\text { control }\end{array}$ & $\begin{array}{l}\text { Secondary } \\
\text { control }\end{array}$ & $\begin{array}{l}\text { Somatic } \\
\text { symptoms }\end{array}$ & $\begin{array}{l}\text { Anxiety } \\
\text { insomnia }\end{array}$ & $\begin{array}{l}\text { Social } \\
\text { dysfunction }\end{array}$ & $\begin{array}{l}\text { Severe } \\
\text { depression }\end{array}$ \\
\hline $\begin{array}{l}\text { Primary } \\
\text { control }\end{array}$ & 1.00 & & & & \\
$\begin{array}{l}\text { Secondary } \\
\text { control }\end{array}$ & $0.60^{* *}$ & 1.00 & & & \\
$\begin{array}{l}\text { Somatic } \\
\text { symptoms }\end{array}$ & $-0.22^{*}$ & $-0.22^{*}$ & 1.00 & & \\
$\begin{array}{l}\text { Anxiety } \\
\text { insomnia }\end{array}$ & $-0.30^{* *}$ & $-0.31^{* *}$ & $0.84^{* *}$ & 1.00 & & \\
$\begin{array}{l}\text { Social } \\
\text { dysfunction }\end{array}$ & $-0.24^{*}$ & $-0.22^{*}$ & $0.55^{* *}$ & $0.56^{* *}$ & 1.00 & \\
$\begin{array}{l}\text { Severe } \\
\text { depression }\end{array}$ & $-0.27^{* *}$ & $-0.23^{*}$ & $0.67^{* *}$ & $0.76^{* *}$ & $0.67^{* *}$ & 1.00 \\
\hline
\end{tabular}

Note: $N=131,{ }^{*} p<0.01,{ }^{*} p<0.001$, one-tailed. 
Table 3. Summary statistics from stepwise multiple regression with overall general adjustment as dependent variable

\begin{tabular}{lllllll}
\hline Predictors & Steps & $\begin{array}{l}\text { Percentage of } \\
\text { accounted for }\end{array}$ & variance & $d f$ & $F$ & $P$ \\
\hline Primary control & 1 & $8.7 \%$ & 1129 & 12.355 & $p<0.001$ \\
View towards ageing & 2 & $3.9 \%$ & 2128 & 9.276 & $p<0.001$ \\
Secondary control & 3 & $1.1 \%$ & 3127 & 6.757 & $p<0.001$ \\
Total & & $13.7 \%$ & & & \\
\hline
\end{tabular}

Summary statistics from stepwise multiple regression with somatic symptoms as dependent variable

\begin{tabular}{lllllll}
\hline Predictors & Steps & $\begin{array}{l}\text { Percentage of } \\
\text { accounted for }\end{array}$ & variance & $d f$ & $F$ & $P$ \\
\hline $\begin{array}{l}\text { Secondary control } \\
\begin{array}{l}\text { View towards ageing and } \\
\text { primary control }\end{array}\end{array}$ & 1 & $4.90 \%$ & 1129 & 6.65 & $p<0.05$ \\
\begin{tabular}{l} 
Total \\
\hline
\end{tabular} & & $3.95 \%$ & 3127 & 4.115 & $p<0.01$ \\
\hline
\end{tabular}

Summary statistics from stepwise multiple regression with anxiety/insomnia as dependent variable

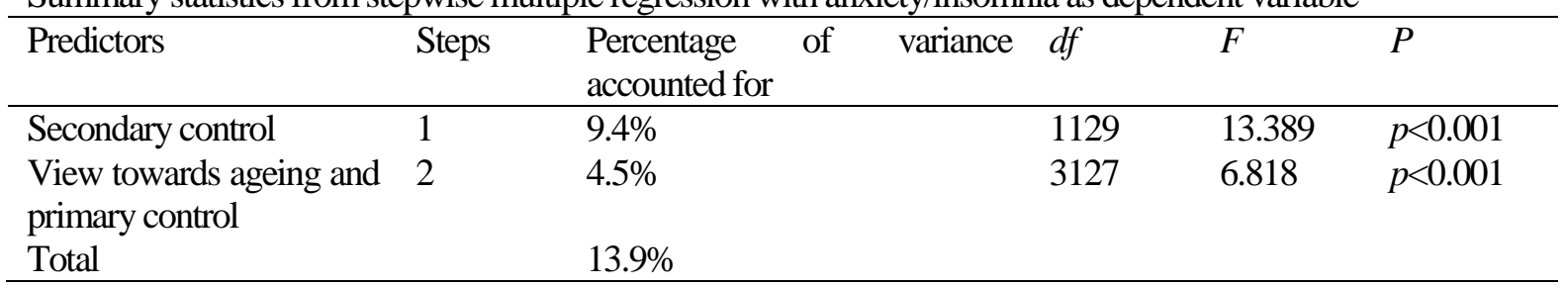

Summary statistics from stepwise multiple regression with social dysfunction as dependent variable

\begin{tabular}{lllllll}
\hline Predictors & Steps & $\begin{array}{l}\text { Percentage of } \\
\text { accounted for }\end{array}$ & variance & $d f$ & $F$ & $P$ \\
\hline Primary control & 1 & $5.7 \%$ & 1129 & 7.852 & $p<0.01$ \\
View towards ageing & 2 & $2.8 \%$ & 2128 & 6.000 & $p<0.005$ \\
Secondary control & 3 & $0.6 \%$ & 3127 & 4.257 & $p<0.01$ \\
Total & & $9.1 \%$ & & & \\
\hline
\end{tabular}

Summary statistics from stepwise multiple regression with severe depression as dependent variable

\begin{tabular}{lllllll}
\hline Predictors & Steps & $\begin{array}{l}\text { Percentage } \\
\text { accounted for }\end{array}$ & variance & $d f$ & $F$ & $P$ \\
\hline Primary control & 1 & $7.2 \%$ & 1129 & 10.058 & $p<0.001$ \\
View towards ageing & 2 & $2.9 \%$ & 2128 & 7.274 & $p<0.001$ \\
Secondary control & 3 & $0.5 \%$ & 3127 & 5.007 & $p<0.001$ \\
Total & & $10.6 \%$ & & & \\
\hline
\end{tabular}

Table 4. Means (M), standard deviations (SD), and Intercorrelations among different control scales

\begin{tabular}{llll}
\hline & Internal-external control & Primary control & Secondary control \\
\hline Internal-external control & 1.00 & & \\
Primary control & $-0.29^{* *}$ & 1.00 & \\
Secondary control & -0.09 & $0.60^{* *}$ & 1.00 \\
M & 9.40 & 2.67 & 2.87 \\
SD & 4.30 & 0.39 & 0.40 \\
\hline
\end{tabular}

Note: $N=131, * * p<0.001$, one-tailed. : Internal-external score refers to numbers of external choices out of 23 items. "9.40" means more internal than external.

Paper to be presented at the $12^{\text {th }}$ International Biophilia Rehabilitation Conference, International Biophilia Rehabilitation Academy, Tokyo, Japan 